\title{
Pulpa Kalsifikasyonları Prevelansının Radyolojik Olarak Değerlendirilmesi
}

\author{
Radiological Evaluation of The Prevalence of Pulp Calcifications
}

\author{
Ali ALTINDAĞ ${ }^{* 1}$ \\ aaltindag@erbakan.edu.tr
}

\author{
İbrahim Burak YÜKSEL ${ }^{1}$ (D) \\ dtburakyuksel@gmail.com
}

\section{öz}

Amaç: Bu çalışmada panoramik görüntülerde dişlerin farklı özelliklerine göre pulpa kalsifikasyonları arasındaki ilişki ve pulpa kalsifikasyonlarının sıklığının belirlenmesi amaçlanmaktadır.

Gereç ve Yöntem: Necmettin Erbakan Üniversitesi Diş Hekimliği Fakültesi Ağız Diş Çene Radyolojisi Bölümüne Ocak 2020-Eylül 2021 tarihleri arasında başvuran 178 hastanın panoramik görüntüleri çalışmada kullanılmıştır. Dişler diş kuronunun durumuna göre (restorasyonlu, restorasyonlu ve çürüklü, "çürüklü", sağlıklı), dişin yer aldığı arkın tarafına göre (sağ, sol) ve dişin bulunduğu çeneye göre (alt, üst) olarak gruplandırılarak pulpa kalsifikasyonunun varlığı değerlendirilmiştir. Elde edilen veriler betimsel istatistikler ve Ki-kare testleri kullanılarak analiz edilmiştir(p<0,05).

Bulgular: 660 sağlam dişin 212'sinde (\%32,2), 210 çürüklü dişin 90'ında (\%42,8), 432 dolgulu dişin 218'inde (\%50,5) ve 84 dolgulu ve çürüklü dişin 44'ünde $(\% 52,4)$ pulpa kalsifikasyonu görülmüștür. Pulpa kalsifikasyonlarının görülmesinde çeneler ve yaş grupları arasında anlamlı bir fark mevcutken cinsiyet ve arkın tarafları arasında anlamlı bir fark gözlenmemiştir.

Sonuç: Pulpa kalsifikasyonu incelenen popülasyonda \%64,6 oranında, en çok dolgulu dişlerde, en az ise dolgulu ve çürüklü dişlerde izlenmiștir.

Anahtar Kelimeler: Panoramik radyografi, Pulpa kalsifikasyonları, Pulpa taşı

$\begin{array}{lll}\text { Geliş: } 03.11 .2021 & \text { Kabul: } 16.12 .2021 & \text { Yayın: } 29.12 .2021\end{array}$

\begin{abstract}
Aim: In this study, it is aimed to determine the relationship between pulp calcifications and the frequency of pulp calcifications according to the different characteristics of the teeth in panoramic images.

Materials and Methods: Panoramic images of 178 patients who applied to Necmettin Erbakan University Faculty of Dentistry Department of Oral and Maxillofacial Radiology between January 2020 and September 2021 were used in the study. The presence of pulp calcification was evaluated by grouping the teeth according to the status of the dental crown (restorated, restored and carious, carious, healthy), according to the side of the arch where the tooth is located (right, left) and according to the jaw in which the tooth is located (lower, upper). Data were analyzed using descriptive statistics and Chi-square tests $(\mathrm{p}<0.05)$.

Results: Pulp calcification was observed in 212 (32.2\%) of 660 healthy teeth, 90 (42.8\%) of 210 caurius teeth, 218 (50.5\%) of 432 restorated teeth and 44 (52.4\%) of 84 restorated and caurius teeth While there was a significant difference between the jaws and age groups in the appearance of pulp calcifications, no significant difference was observed between gender and the sides of the arch. Conclusion: Pulp calcification was observed at a rate of $64.6 \%$ in the studied population, mostly in restorated teeth and least in restorated and caurius teeth.
\end{abstract}

Keywords: Panoramic radiography, Pulp calcification, Pulp stone

$\begin{array}{lll}\text { Received: 03.11.2021 Accepted: } 16.12 .2021 & \text { Published: } 29.12 .2021\end{array}$

Atıf / Citation: Altındağ A, Yüksel İB. Pulpa kalsifikasyonları prevelansının radyolojik olarak değerlendirilmesi . NEU Dent J. 2021;3:102-7.

* Sorumlu Yazar / Corresponding Author

1. Necmettin Erbakan Üniversitesi Diş Hekimliği Fakültesi Ağız, Diş ve Çene Radyolojisi AD Konya, Türkiye
"This article is licensed under a Creative Commons AttributionNonCommercial 4.0 International License(CC BY-NC 4.0) 


\section{GİRIŞ}

Pulpa kalsifikasyonlarının etyolojisi tam olarak bilinmemekle birlikte gelişmesinde rol alan etkenler; epitel-pulpa etkileșimi, pulpadaki dolașım bozukluğu, dejenerasyonlar, periodontal hastalık, çürük, ortodontik tedavi, kronik enflamasyon, yaş, cinsiyet, genetik yatkınlık ve idiopatik olarak sıralanmaktadır. ${ }^{1,2}$ Pulpa kalsifikasyonu daimi diște, süt dişinde, sürmemiș diște, sağlıklı ya da defektli diște görülebilen, tek bir dişte oluşabileceği gibi tüm dentisyonda da oluşabilen pulpa içindeki kalsifiye yığınlardır. ${ }^{3,4}$

Pulpa kalsifikasyonları, pulpa sklerozu/diffüz kalsifikasyon (distrofik kalsifikasyon) ve pulpa tașı (dentikel) olmak üzere sınıflandırılmaktadır., ${ }^{5,6}$ Pulpa sklerozu pulpadaki sinir kılıflarında, kan pıhtılarında, dejenere hücrelerin çevresinde ve kollajen fibrillerin çevresinde meydana gelen, pulpa taşının aksine lokalize değil yaygın bir şekilde oluşan, sınırları diffüz kalsifikasyonlardır ve pulpa odasında görülmekle birlikte kök kanalında da oluşmaktadır (Resim 1) ${ }^{4,7}$
Pulpa taşları genellikle yuvarlak ve oval şekillidir (Resim 2). Sınırları sıklıkla düzgündür, ancak düzensiz sınırlı da olabilmektedir. ${ }^{1,8}$ Çok küçük ebatlardan, pulpa odasını kaplayacak ebatlara kadar boyutları çeşitlilik göstermektedir. Ayrıca birkaç küçük pulpa taşının birleşmesiyle oluşan büyük pulpa taşları da görülmektedir. Pulpa taşları lokalizasyonlarına ve yapılarına göre sinıflandırılmaktadır. Lokalizasyonlarına göre gömük, yapışık ve serbest olarak üçe ayrilırken, yapılarına göre gerçek ve sahte olmak üzere ikiye ayrılmaktadır. ${ }^{8-10}$ Gömük pulpa taşı bütünüyle dentin içine gömülüyken yapışık pulpa taşı bir kenarı ile dentinle bağlantı halindedir. Yapışık ve gömük pulpa taşlarına kök gelişimi tamamlanmış dişlerde rastlanırken serbest pulpa taşlarına kök gelişimi tamamlanmamıș dișlerde rastlanmaktadır.,11 Gerçek pulpa taşı dentine benzeyen biyokimyasal yapıda olup periferindeki odontoblastlar tarafından üretilmektedir ve genellikle pulpanın kuronal kısmında bulunmaktadır.,12 Sahte pulpa tașı ise dentin kanalı içermez, periferinde odontobalastlar bulunmaz, dejenere olmuş pulpa hücrelerinden oluşur ve genellikle kök pulpasında bulunmaktadır.,10

Resim 1: Panoramik görüntüde molar dişlerde pulpa sklerozu

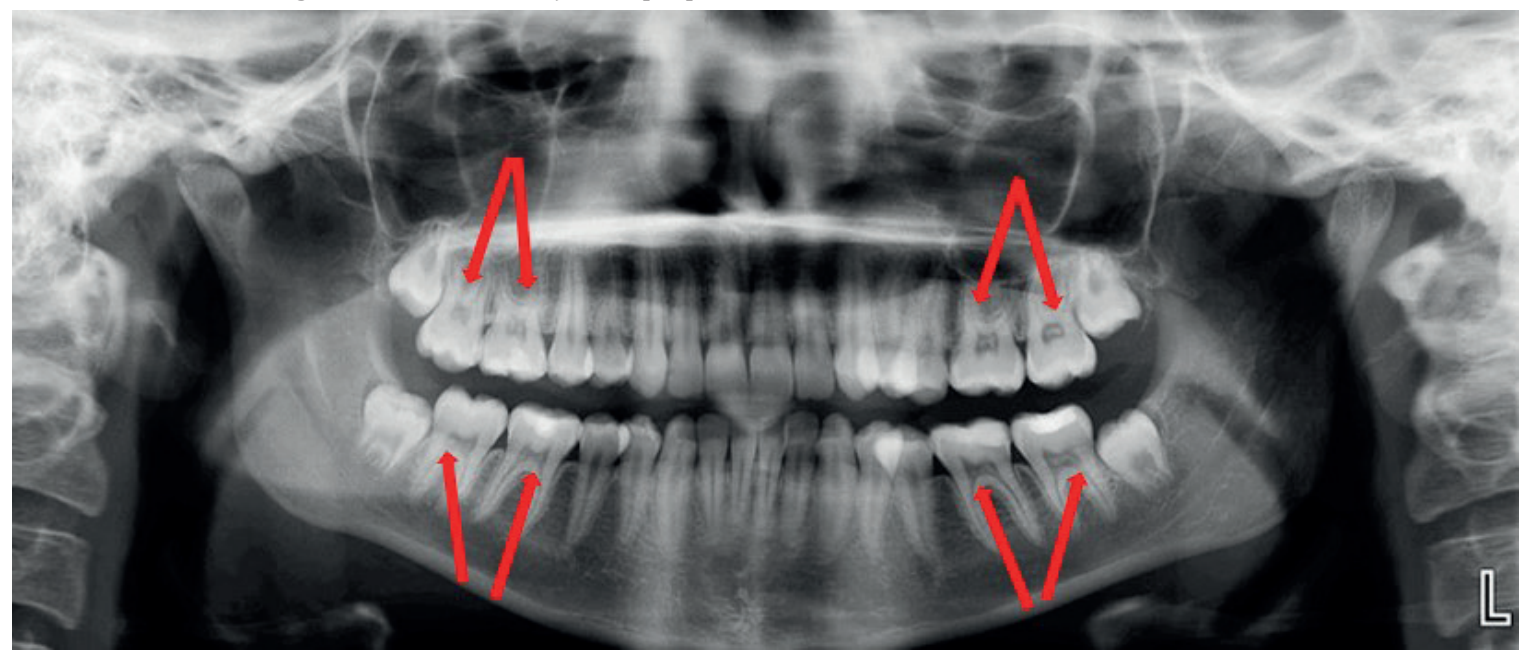

Resim 2: Kırpılmış panoramik görüntülerde molar dişlerde yuvarlak ve oval şekilli pulpa taşları
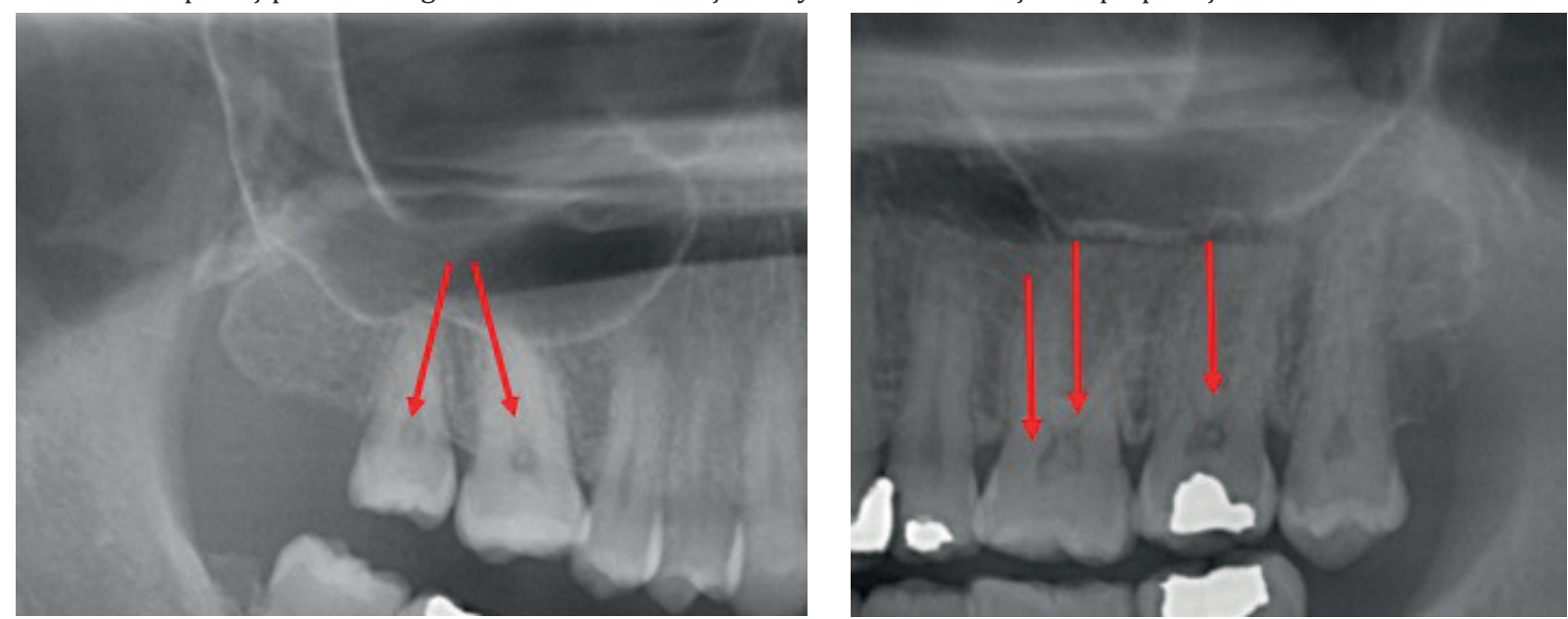
Pulpa tașları ve pulpa sklerozu klinik olarak belirti vermezler ve rutin radyolojik muayenede belirli bir boyuta $(>200 \mu \mathrm{m})$ ve mineralizasyon derecesine ulaștıktan sonra tespit edilmektedirler.5,6 Pulpa taşları çoğunlukla molar dişlerde görülmelerine rağmen diğer diş gruplarında görülmektedir. ${ }^{6}$ Tedavi edilmelerine gerek yoktur ancak endodontik tedavi uygulamalarında zorluğa neden olmaktadırlar. ${ }^{5,12,13}$

$\mathrm{Bu}$ çalışmanın amacı; bir grup Türk toplumunda birinci ve ikinci molar dişlerdeki pulpa kalsifikasyonlarının sıklı̆̆ını panoramik görüntüler üzerinden tespit etmek, pulpa kalsifikasyonlarının yaș, cinsiyet, diş kuronunun durumları ve çeneler arasındaki ilişkilerini belirlemektir.

\section{GEREÇ VE YÖNTEMLER}

Araştırma için Necmettin Erbakan Üniversitesi Diş Hekimliği Fakültesi İlaç ve Tibbi Cihaz Dışı Araştırmalar Etik Kurulu'ndan 2021/10-86 numaralı karar ile etik kurul onayı alınmıştır. Bu retrospektif çalışmada, Ocak 2020 - Eylül 2021 tarihleri arasında Necmettin Erbakan Üniversitesi Diş Hekimliği Fakültesi Ağız Diş ve Çene Radyolojisi bölümüne farklı nedenlerle başvuran hastalara ait panoramik görüntüler rastgele seçilmiştir. Panoramik radyografiler Morita Veraviewepocs 2D panoramic unit (J Morita MFG Corp., Kyoto, Japan) cihazı ile 60-70 kVp, 5-7 mA ve 6-8 s ekspoz sürelerinde, üretici firmanın tavsiyelerine göre alınmıștır. Tüm veriler iki maksillofasiyal radyolog (AA ve İBY) tarafından LCD monitörde ortam ışığında değerlendirilmiştir. Her bir bulgunun nihai sınıflandırması ve radyografik durumu, gözlemciler arası konsensus sonrası kaydedilmiştir. Hastaların demografik bilgilerini içermeyen, görüntü kalitesi düşük ve artifaktlı radyografiler çalışmaya dahil edilmemiştir. Çalışmada, 16 yaş ve üzeri hastaların diagnostik olarak kabul edilebilir görüntüleri kullanılmıștır. Taranan 200 görüntüden 178 tanesi çalışmaya dahil edilmiştir. Değerlendirilen dişler diş kuronunun durumuna göre (restorasyonlu, restorasyonlu ve çürüklü, çürüklü, sağlıklı), dişin yer aldığı tarafına göre (sağ, sol) ve dişin bulunduğu çeneye göre (alt, üst) olarak sınıflandırılmıştır.

Pulpa kalsifikasyonlarının görülme sıklığı ile cinsiyet, yaş, diş durumları ve diş konumları arası iliş̧kiler ki-kare testi ve betimsel istatistikler ile değerlendirilmiştir. Analizlerin uygulanmasında IBM SPSS Statistics 21.0 programı kullanılmıștır. İstatistiksel önemlilik için $\mathrm{p}<0.05$ değeri kriter kabul edilmiştir.

\section{BULGULAR}

Çalışmamızda 92 erkek, 86 kadın toplam 178 hastanın 1386 molar dişi değerlenmiştir. Pulpa taşı tespit edilen hastaların yaşlarına ilişkin bazı tanımlayıcı istatistikler Tablo 1'de cinsiyete göre özetlenmiştir.
Tablo 1: Hastaların yașı için betimsel istatistikler

\begin{tabular}{|l|l|l|l|}
\hline & Kadın & Erkek & Toplam \\
\hline Sayı & 86 & 92 & 178 \\
\hline Ortalama & 31,83 & 30 & 30,88 \\
\hline Standart Sapma & 14,77 & 13,08 & 14,42 \\
\hline Medyan & 25 & 28 & 26 \\
\hline En Küçük Değer & 16 & 16 & 16 \\
\hline En Büyük Değer & 71 & 66 & 71 \\
\hline
\end{tabular}

Değerlendirilen 660 sağlam dişin 212'sinde (\%32,2), 210 çürüklü dişin 90'ında (\%42,8), 432 dolgulu dişin 218'inde $(\% 50,5)$ ve 84 dolgulu ve çürüklü dişin $44^{\prime}$ ünde $(\% 52,4)$ pulpa taşı ve pulpa sklerozu tespit edilmiştir (Tablo 2). Diş kuronunun çeşitli durumlarına göre pulpa taşı varlığı istatistiksel olarak anlamlı $(\mathrm{p}=0,001)$ bulunmuştur.

Tablo 2: Diş durumlarına ve pulpa kalsifikasyon çeşitleri için çapraz tablo ve ki-kare testi (eksik dişler hariç)

\begin{tabular}{|c|c|c|c|c|}
\hline & \multicolumn{4}{|c|}{ Kalsifikasyon Çeşitleri } \\
\hline $\begin{array}{c}\text { Diş } \\
\text { Durumları }\end{array}$ & $\begin{array}{c}\text { Pulpa } \\
\text { Taşı }\end{array}$ & $\begin{array}{c}\text { Pulpa } \\
\text { Sklerozu }\end{array}$ & Yok & Toplam \\
\hline Sağlam & 174 & 38 & 448 & 660 \\
\hline Çürüklü & 74 & 16 & 120 & 210 \\
\hline Dolgulu & 180 & 38 & 214 & 432 \\
\hline $\begin{array}{c}\text { Dolgulu ve } \\
\text { Çürüklü }\end{array}$ & 32 & 12 & 40 & 84 \\
\hline Toplam & 460 & 104 & 822 & 1386 \\
\hline & $\chi^{2}=22,760$, s.d. $=6, p=0,001$ & \\
\hline
\end{tabular}

Diş arkının sağ tarafındaki 220 dişte pulpa taşı, 54 dişte pulpa sklerozu, diş arkının sol tarafındaki 240 dişte pulpa taşı, 50 dişte pulpa sklerozu tespit edilmiştir (Tablo 3). Arkın sağ ve sol tarafları arasında istatiksel olarak anlaml bir fark bulunmazken $(p=0,789)$ alt çene ve üst çene olarak değerlendirildiğinde üst çenede 314 diște pulpa taşı, 30 dişte pulpa sklerozu, alt çenede 146 diște pulpa taşı, 74 dişte pulpa sklerozu tespit edilmiştir (Tablo 4) ve çeneler arasında istatistiksel olarak anlamlı bir fark gözlenmiştir $(\mathrm{p}=0,000)$.

Tablo 3: Diş arkının konumuna göre ve pulpa kalsifikasyon çeşitleri için çapraz tablo ve ki-kare testi

\begin{tabular}{|c|c|c|c|c|}
\hline & \multicolumn{4}{|c|}{ Kalsifikasyon Çeşitleri } \\
\hline $\begin{array}{c}\text { Diş } \\
\text { Konumları }\end{array}$ & $\begin{array}{c}\text { Pulpa } \\
\text { Taşı }\end{array}$ & $\begin{array}{c}\text { Pulpa } \\
\text { Sklerozu }\end{array}$ & Yok & Toplam \\
\hline Să̆ & 220 & 54 & 438 & 712 \\
\hline Sol & 240 & 50 & 422 & 712 \\
\hline Toplam & 460 & 104 & 860 & 1424 \\
\hline & $\chi^{2}=0,473$, s.d. $=2, p=0,789$ & \\
\hline
\end{tabular}


Tablo 4: Dișlerin bulunduğu çeneler ve pulpa kalsifikasyon çeşitleri için çapraz tablo ve ki-kare testi

\begin{tabular}{|c|c|c|c|c|}
\hline & \multicolumn{4}{|c|}{ Kalsifikasyon Çeşitleri } \\
\hline $\begin{array}{c}\text { Diş } \\
\text { Konumları }\end{array}$ & $\begin{array}{c}\text { Pulpa } \\
\text { Taşı }\end{array}$ & $\begin{array}{c}\text { Pulpa } \\
\text { Sklerozu }\end{array}$ & Yok & Toplam \\
\hline Maksilla & 314 & 30 & 368 & 712 \\
\hline Mandibula & 146 & 74 & 492 & 712 \\
\hline Toplam & 460 & 104 & 860 & 1424 \\
\hline
\end{tabular}

Pulpa kalsifikasyonları, cinsiyete göre değerlendirildiğinde anlamlı bir fark $(\mathrm{p}=0,075)$ bulunmazken (Tablo 5) yaş gruplarına göre (Tablo 6) gruplar arasında istatistiksel olarak anlamlı bir fark bulunmuştur $(\mathrm{p}=0,000)$.

Tablo 5: Cinsiyet ve pulpa kalsifikasyon çeşitleri için çapraz tablo ve ki-kare testi

\begin{tabular}{|c|c|c|c|c|}
\hline & \multicolumn{4}{|c|}{ Kalsifikasyon Çeşitleri } \\
\hline Cinsiyet & $\begin{array}{c}\text { Pulpa } \\
\text { Taşı }\end{array}$ & $\begin{array}{c}\text { Pulpa } \\
\text { Sklerozu }\end{array}$ & Yok & Toplam \\
\hline Erkek & 250 & 40 & 446 & 736 \\
\hline Kadın & 210 & 64 & 414 & 688 \\
\hline Toplam & 460 & 104 & 860 & 1424 \\
\hline
\end{tabular}

Tablo 6: Hastaların yaș grupları için çapraz tablo ve ki-kare testi

\begin{tabular}{|c|c|c|c|c|}
\hline & \multicolumn{4}{|c|}{ Kalsifikasyon Çeşitleri } \\
\hline Yaş Grupları & $\begin{array}{c}\text { Pulpa } \\
\text { Taşı }\end{array}$ & $\begin{array}{c}\text { Pulpa } \\
\text { Sklerozu }\end{array}$ & Yok & Toplam \\
\hline $\mathbf{1 6 - 3 0}$ & 220 & 28 & 568 & 816 \\
\hline $\mathbf{3 1 - 5 0}$ & 172 & 39 & 213 & 424 \\
\hline $\mathbf{5 1 +}$ & 86 & 37 & 79 & 184 \\
\hline Toplam & 460 & 104 & 860 & 1424 \\
\hline
\end{tabular}

\section{TARTIŞMA}

Pulpa taşları-sklerozları pulpa dokusu içerisindeki dentin yapısına benzeyen kalsifikasyonlardır ve gelişim nedeni kesin olarak ortaya koyulmamıştır. Pulpa taşları-sklerozları sıklıkla radyograflarda rastlantısal bir bulgu olarak görülmektedir. ${ }^{14}$ Boyutları 200 $\mu$ m'dan küçük olan pulpa taşları radyolojik olarak tespit edilemese de histolojik yöntemlere göre invaziv olmaması nedeniyle çalışmalarda sıklıkla radyolojik yöntemler tercih edilmektedir. ${ }^{11} \mathrm{Bu}$ nedenle çalışmamız çeșitli dental sebeplerle panoramik radyografileri çekilmiș hastaların görüntüleri üzerinden gerçekleştirilmiştir.
Çalışmamızda 86 kadın hastanın 58'inde (\%67,4), 92 erkek hastanın 57'sinde $(\% 61,9)$ pulpa kalsifikasyonu tespit edilmiștir ve iki cinsiyet arasında istatistiksel olarak anlamlı bir fark bulunmamıştır $(p=0,075)$. Çalışmamızdan farklı olarak pulpa kalsifikasyonu görülme oranı Şişman ve ark. ${ }^{14}$ tarafından yapılan bir çalışmada kadınlarda $\% 10,5$ ve erkeklerde $\% 4,4$ olarak tespit edilmiş ve cinsiyetler arasında anlamlı bir fark bulunduğu ortaya koyulmuştur. Şener ve ark. ${ }^{3}$ benzer şekilde pulpa kalsifikasyonu görülme sıklığını kadınlarda daha fazla bulmuşlar ve bruksizmin kadınlarda erkeklere oranla fazla görülmesi nedeniyle pulpa kalsifikasyonlarının bruksizmle bağlantılı olabileceğini, bu bağlamda ileri çalışmalarda bu olasılığın değerlendirilmesini önermişlerdir. Taşsöker ${ }^{15}$ tarafından yapılan çalıșmada ise pulpa kalsifikasyonlarının meydana gelmesinde bruksizmin risk faktörü olmadığı sonucuna ulaşılmıștır.

Çalışmamızda pulpa kalsifikasyonları ve diş durumları arasında anlamlı bir ilişki bulunmuştur $(p=0,001)$. Bu sonuç literatürdeki birçok çalışma ile uyumludur. ${ }^{3,11,16}$ Ancak sağllklı dişlerde ve henüz herhangi bir irritana maruz kalmamış (sürmemiş dişler) dişlerde de pulpa kalsifikasyonu görülmektedir. Bazı çalışmalarda, değinilen bulguları destekler nitelikte diş durumları ve pulpa kalsifikasyonları arasında anlamlı bir fark bulunmamıștır., ${ }^{2,10,17}$

Dişlerde, arkta bulunduğu tarafa göre (sağ-sol) pulpa kalsifikasyonu görülmesi istatistiksel olarak anlamlı bulunmazken çeneler arası anlamlı bir fark tespit edilmiştir. Çalışmamızda üst çenede alt çeneye göre daha sık pulpa kalsifikasyonu gözlenmiştir. Literatürdeki bazı araştırmalar bu sonucu desteklemektedir. ${ }^{7,11}$ Ancak pulpa kalsifikasyonlarının alt çenede daha sık görüldüğünü bildiren çalışmalar da mevcuttur. $^{16}$

Çalışmamızda 16-30, 31-50, 51 ve üzeri olmak üzere üçe ayrılan yaş grupları arasında anlamlı bir fark tespit edilmiştir. Bazı çalışmalarda yaş grupları arasında anlamlı bir fark bulunmazken ${ }^{3,18}$ bazı çalışmalarda yaș grupları arasında anlamlı bir fark bulunmuștur. 2,19-21 Ancak değinilen çalışmalar yaşla birlikte pulpa taşı görülme sıklığının arttığını belirtmişlerdir. Çalışmamızda ise pulpa kalsifikasyonları en sık 16-30 yaș grubunda görülürken en az 51 ve üzeri yaș grubunda görülmüștür.

Pulpa kalsifikasyonlarının sıklığı literatürde diş bazında değerlendirildiğinde görülme sıklığı \%2,1 ile $\%$ 27,8 arasında tespit edilmiştir. ${ }^{22}$ Ancak çalışmamızda literatürden farklı olarak \%40,58 olarak belirlenmiștir. Türk popülasyonunda yapılan pulpa taşı çalışmalarında diş bazında değerlendirmede Şener ve ark. ${ }^{3} \% 4,8$; Gülşahı ve ark. ${ }^{2} \% 5$; Şişman ve ark. ${ }^{14}$ \%15; Çolak ve ark. ${ }^{19} \% 27,8$ olarak bulmuşlardır. Kişi 
bazında yapılan değerlendirmede ise çalışmamızda 178 hastanın 115 'inde $\% 64,6$ olarak pulpa kalsifikasyonu tespit edilmiștir. Bu sonuç Çolak ve ark. ${ }^{19}$ kiși bazında yaptığı değerlendirme $(\% 63,6)$ ile uyumlu iken Gülşahı ve ark. ${ }^{2} \% 12$; Şener ve ark. ${ }^{3} \% 38$; Şişman ve ark. ${ }^{14}$ yaptıkları çalış̧malardan yüksektir. Pulpa kalsifikasyonlarının sıklığı etnik köken ve coğrafi özelliklere bağlı olarak değișebilmektedir. Ayrıca pulpa kalsifikasyonları değerlendirilirken kullanılan görüntüleme çeşidi ve teknik de tespit edilmelerini etkilemektedir. $^{21}$

Pulpa kalsifikasyonu sıklığını araştıran çalıșmalar arasında farklılık olmasının bir nedeni de çalışmanın tasarımından kaynaklanmaktadır. Sezgin ve ark. ${ }^{10}$ yaptıkları çalışmada pulpa taşını diş sayısına bağlı olarak değerlendirmişler ve sıklığını \%10,5 olarak bulmuşlardır. Ancak çalışmalarında anterior, kanin, premolar ve molar olmak üzere tüm diş gruplarındaki pulpa taşı varlığını değerlendirmişlerdir. Çalışmamızda ise Sezgin ve ark.'dan farklı olarak pulpa kalsifikasyonlarının daha sık görüldüğü molar dişler değerlendirmeye dahil edilmiştir.

Çalıșmamızda pulpa kalsifikasyonu ve sistemik hastalık arasındaki ilişkinin değerlendirilmemesi çalışmamızın sınırlamalarını oluşturmaktadır. Bazı çalışmalar ${ }^{1,7,17,23}$ sistemik hastalıklar ile pulpa kalsifikasyonu arasında anlamlı ilişki bulunduğunu bildirirken bazı çalıșmalar ${ }^{24,25}$ ise anlamlı bir ilișki olmadığını bildirmişlerdir. Pulpa kalsifikasyonları ve sistemik rahatsızlıklar arasındaki ilişkinin doğrulanması için daha çok sayıda araştırmaya gereksinim vardır.

\section{SONUÇ}

Çalışmamızın limitasyonları dahilinde;

- Pulpa kalsifikasyonları incelenen popülasyonda hasta bazında \%64,6 diș bazında \%40,58 sıklığa sahiptir.

- Dişin dental arkın hangi tarafında bulunduğu ve cinsiyet pulpa kalsifikasyonunun görülme sıklığını etkilememektedir.

- Diş kuronun farklı durumları, dişlerin bulundugu çene ve yaș faktörleri pulpa kalsifikasyonlarının sıklığını etkilemektedir.

Pulpa kalsifikasyonları ile ilgili netlik kazanmamıș birçok konu bulunduğu görülmektedir. Bu nedenle bu konu üzerinde geniş örneklem büyüklüklerinde ve daha çok çalışmaya ihtiyaç vardır.

\section{KAYNAKLAR}

1. Goga R, Chandler NP, Oginni AO, Pulp stones: a review. Int Endod J. 2008;41:457-468.

2. Gulsahi A, Cebeci AI, Ozden S. A radiographic assessment of the prevalence of pulp stones in a group of Turkish dental patients. Int Endod J. 2009;42:735739.

3. Sener S, Cobankara FK, Akgunlu F. Calcifications of the pulp chamber: prevalence and implicated factors. Clin Oral Investig. 2009;13:209-215.

4. Johnson PL, Bevelander DR. Histogenesis and histochemistry of pulpal calcification. J Dent Res. 1956;35:714-722.

5. Harorlı A. Ağız, Diş ve Çene Radyolojisi. 1. Baskı İstanbul:Nobel; 2014.p.309.

6. White SC, Pharoah MJ. Oral radiology: principles and interpretation. 7. Baskı Ankara:Palme; 2014.p.606608.

7. Nayak M, Kumar J, Prasad LK. A radiographic correlation between systemic disorders and pulp stones. Indian J Dent Res. 2010;21:369-373.

8. Deva V, Mogonta L, Manolea H, Panca OA, Vatu M, Vataman M. Radiological and microscopic aspects of the denticles. Rom J Morphol Embryol. 2006;47:263-268.

9. Ingle J, Bakland L. Endodontics 4th, Edition. Williams \& Wilkins, Baltimore. 1994;337

10. Sezgin B, Cakan EF, Erdem TL. A Radiographic Assessment of The Prevalence and Distribution of Pulp Calcification. J Istanbul Univ Fac Dent. 2011;45:49-55.

11. Ranjitkar S, Taylor JA, Townsend GC. A radiographic assessment of the prevalence of pulp stones in Australians. Aust Dent J. 2002;47:36-40.

12. Pindborg JJ. Pathology of the dental hard tissues. Copenhagen;Munksgaard; 1970.p.353-355.

13. Abbott $\mathrm{P}, \mathrm{Yu} \mathrm{C}$. A clinical classification of the status of the pulp and the root canal system. Aust Dent J. 2007;52:S17-S31.

14. Sisman Y, Aktan AM, Tarım-ertas E, Ciftci ME, Sekerci AE. The prevalence of pulp stones in a Turkish population. A radiographic survey. Medicina Oral Patologia Oral y Cirugia Bucal 2012;17:212-217.

15. Tassoker M. Evaluation of the relationship between sleep bruxism and pulpal calcifications in young women: A clinico-radiological study. Imaging Sci Dent. 2018;48:277-281.

16. Baghadi VS, Ghose LJ, Nahoom HY. Prevalence of pulp stones in a teenage Iragi group. J Endod. 1988;14:309311.

17. Bauss O,Neter D, Rahman A. Prevalence of pulp calcifications in patients with Marfan syndrome. Oral surg Oral Path Oral Radiol and Endod. 2008;106:e56-e61.

18. Ilday NO, Miloglu O, Demirtas O, Yildirim E, seven N, Omer S. A radiographic assessment of the prevalence of pulp stones in patients who presented to ataturk university faculty of dentistry department of oral diagnosis and radiology. J Istanbul Univ Fac Dent. 2014;48: 9-16.

19. Colak H, Celebi AA, Hamidi MM, Bayraktar Y, Colak T, Uzgur R. Assessment of the prevalence of pulp stones in a sample of Turkish Central Anatolian population. Scientific World J. 2012;2012:804278. 
20. Hamasha AAH, Darwazeh A. Prevalence of pulp stones in Jordanian adults. Oral Surg Oral Med Oral Path Oral Radiol Endod. 1998;86:730-732.

21. Udoye CI, Sede MA. Prevalence and analysis of factors related to occurrence of pulp stone in adult restorative patients. Ann Med Health Sci Res. 2011;1:9-14.

22. Jannati R, Afshari M, Moosazadeh M, Allahgholpour SZ, Eidy M, Hajihoseini M. Prevalence of pulp stones: A systematic review and meta-analysis. J Evid Based Med 2019;12:133-139.

23. Edds AC, Walden JE, Scheetz JP, Goldsmith LJ, Drisko CL, Eleazer PD. Pilot study of correlation of pulp stones with cardiovascular disease. J Endod. 2005;31:504-506.
24. Kansu O, Ozbek M, Avcu N, Aslan U, Kansu H, Genctoy G. Can dental pulp calcification serve as a diagnostic marker for carotid artery calcification in patients with renal diseases? Dentomaxillofac Radiol. 2009;38:542-545.

25. Horsley SH, Beckstrom B, Clark Sj, Scheetz JP, Khan Z, Farman AG. Prevalence of carotid and pulp calcifications: a correlation using digital panoramic radiographs. Int J Comput Assist Radiol Surg. 2009;4:169173. 